\title{
Entrevistas e análise de metais pesados ao longo do rio Doce
}

Claudia Camilo de Oliveira* Björn Krause Camilo

Universidade Federal de São Paulo (UNIFESP) Campus Baixada Santista - Unidade I Av. Ana Costa, $95-1^{\circ}$ Andar - Vila Mathias Santos SP Brasil CEP 11060-001

${ }^{*}$ Autora correspondent camiloclaudia34@gmail.com

\section{RESUMO}

Considerando um panorama com poucos estudos científicos que apresentassem um paralelo entre as percepções das pessoas atingidas pelo rompimento da barragem do Fundão, em Mariana, Minas Gerais, Brasil, e as concentrações de metais pesados presentes nos locais atingidos ao longo da bacia do Rio Doce, esse estudo teve como objetivo identificar essa relação. Os métodos utilizados foram entrevistas semiestruturadas com pessoas atingidas e coleta de amostras de água e sedimento do rio ao longo da bacia do Rio Doce para medir a concentração de metais pesados. O sedimento foi processado de acordo com o método EPA 3051-16 (Environmental Protection Agency). Os metais pesados na água e no sedimento foram analisados com ICP-AES (Inductively Coupled Plasma - Atomic Emission Spectrometry) e AAS (Atomic Absorption Spectrometry) no IGC/UFMG (Instituto de Geociências / Universidade Federal de Minas Gerais) e na COPASA (Companhia de Saneamento de Minas Gerais). As amostras de água mostraram concentrações excessivas para Al (alumínio), Fe (ferro) e Mn (manganês) em um rio da Classe II do CONAMA (Conselho Nacional do Meio Ambiente, 2009). As amostras de sedimento continham Zn (zinco), $\mathrm{Cr}$ (cromo), $\mathrm{Cu}$ (cobre) e $\mathrm{Pb}$ (chumbo) reversivelmente conectados acima do valor de referência de qualidade da CETESB (Companhia Ambiental do Estado de São Paulo, 2005). As entrevistas foram analisadas pelo método de Análise de Conteúdos e apontaram para desinformação dos atingidos em relação aos metais pesados no rio Doce. $\mathrm{O}$ estudo mostrou que a lama contribuiu para a contaminação de metais pesados na bacia do Rio Doce, principalmente com a relocação e a liberação de contaminantes já existentes nos sedimentos. As pessoas atingidas devem ser informadas sobre a contaminação de metais pesados nos rios, solos e sobre a mudança da concentração de metais pesados ao longo dos anos.

Palavras-chave: Rompimento da barragem do Fundão, entrevistas, metais pesados

\section{ABSTRACT}

Given a panorama of few studies that paralleled the perceptions of people affected by the Fundão dam rupture in Mariana, Minas Gerais, Brazil, and the concentrations of heavy metals present in the affected areas along the Doce River, this study aimed to identify this relationship. The methods used were semi-structured interviews with affected people and collection of water and sediment samples from the river along the Rio Doce basin to measure the concentration of heavy metals. The sediment was processed according to EPA 3051-16 (Environmental Protection Agency) method. Heavy metals in the water and sediment were analyzed with ICP-AES (Inductively Coupled Plasma - Atomic Emission Spectrometry) and AAS (Atomic Absorption Spectrometry) at IGC / UFMG (Institute of Geosciences / Federal University of Minas Gerais) and COPASA (Minas Gerais Sanitation Company). Water samples showed excessive concentrations for Al (aluminum), Fe (iron) and Mn (manganese) in a Class II river according to CONAMA (National Environmental Council, 2009). Sediment samples contained Zn (zinc), $\mathrm{Cr}$ (chrome), $\mathrm{Cu}$ (copper) and $\mathrm{Pb}$ (lead) reversibly connected above the quality reference value according to CETESB (São Paulo State Environmental Company, 2005). The interviews were analyzed by the Content Analysis method and pointed to the misinformation of those affected in relation to the heavy metals in the Doce River. The study showed that the mud contributed to the contamination of heavy metals in the affected rivers, mainly by 
relocation and release of contaminants already existing in sediments. Affected persons should be informed about heavy metal contamination in rivers and soils and about the change in heavy metal concentration over the years.

Keywords: Fundão dam rupture, interviews, heavy metals

\section{INTRODUÇÃO}

Este estudo foi realizado em 2016, após o rompimento da barragem de Fundão, próximo a Bento Rodrigues, no município de Mariana, Minas Gerais, em 5 de novembro de 2015, considerado então, o trágico acontecimento socioambiental mais grave na história do Brasil. A barragem de Fundão é controlada pela Samarco Mineração S. A., um empreendimento conjunto das empresas de mineração Vale S. A. (brasileira) e BHP Billiton (anglo-australiana). Aproximadamente $663 \mathrm{~km}$ de rio na bacia do Rio Doce, em 36 municípios, foram atingidos com os resíduos da mineração- denominado como "lama" (RUSSAU, 2016; FREITAS et al., 2019). Dezenove (19) pessoas morreram, centenas de pessoas perderam suas casas, tendo que ser relocadas, milhares de pessoas sofreram perdas econômicas, perderam a base de seus recursos de renda, como por exemplo, no turismo, na pescaria, entre outros (RUSSAU, 2016). Os indígenas Guaranis e Krenak sofreram perdas socioculturais (ibid., p. 127). O rompimento da barragem e a lama causaram doenças físicas e psíquicas, extinção de espécies e cobertura de muitos hectares de sedimentos e solos (RUSSAU, 2016; FREITAS et al., 2019).

Nas primeiras semanas após o rompimento, estabeleceram-se diversas discussões polêmicas sobre os danos socioambientais (SANTOS et al., 2019). $\mathrm{Na}$ questão

\section{MÉTODO}

\subsection{ENTREVISTAS}

O método para coleta de dados sobre as percepções das pessoas atingidas, após o rompimento da barragem do Fundão, foi a entrevista semiestruturada. Para análise dos dados coletados, foi utilizada a abordagem qualitativa de Análise de Conteúdos, proposta por Bardin (BARDIN, 1979). Optou-se pela entrevista semiestruturada, já que as pessoas geoquímica, havia os que consideravam a lama de rejeitos capaz de envenenar as águas e os solos com metais pesados e os que atestavam que a lama seria inerte, ou seja, não seria fonte de elementos inorgânicos, que podem ser perigosos para a saúde humana e para o meioambiente, com exceção do ferro, que é um elemento geogenicamente elevado nos compartimentos naturais da bacia do Rio Doce (RUSSAU, 2016).

No período pós-rompimento da barragem de Fundão, seis (6) meses depois do ocorrido, abril de 2016, havia pouca publicação científica a respeito da qualidade da água, da lama e do solo, bem como poucos estudos científicos feitos com a população atingida.

Diante desse panorama, o objetivo deste estudo foi relacionar as percepções das pessoas atingidas, após o rompimento da barragem, com a mensuração das concentrações de metais pesados na água, na lama e no sedimento ao longo da bacia do Rio Doce. Este estudo trata somente o caso do rompimento da barragem de Fundão, no município de Mariana, contribuindo para a discussão entre órgãos envolvidos (empresas, estado, mídia, etc.), por meio de uma investigação que considera a perspectiva das pessoas atingidas e a realidade das concentrações de metais pesados nas águas, na lama e nos sedimentos ao longo da bacia do Rio Doce (Figura 1).

atingidas têm a possibilidade de discorrer sobre suas experiências, a partir do foco principal proposto pelos pesquisadores, e, ao mesmo tempo, esse tipo de entrevista permite respostas livres e espontâneas, ampliando a coleta de dados para tópicos que, a princípio, não teriam sido pensados pelos pesquisadores. 


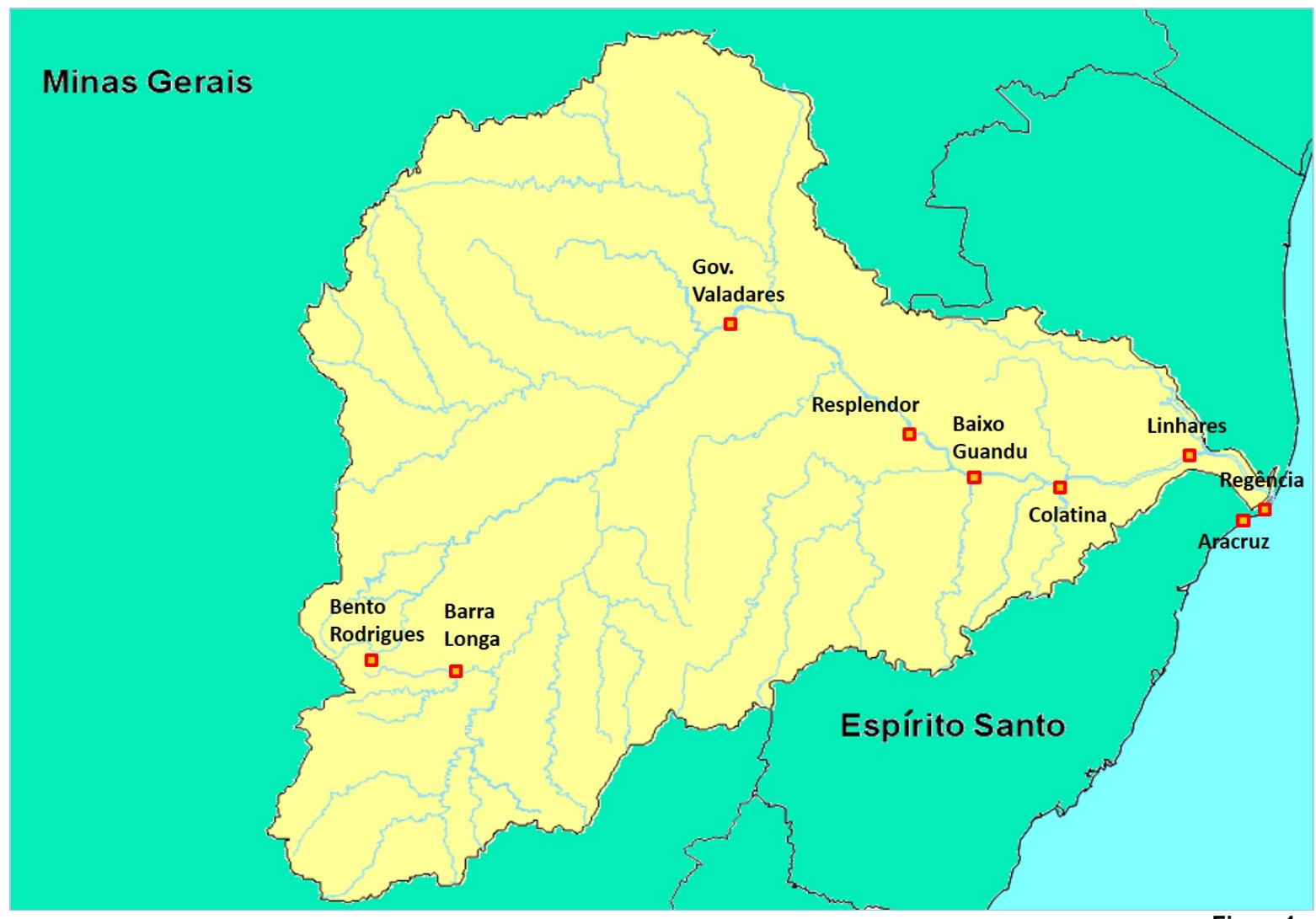

Figura1

Os locais das entrevistas e coletas das amostras da lama, dos sedimentos e das águas da Bacia do Rio Doce Fonte: https://commons . wikimedia.org/w/index. php?curid=10870947.

A fase de preparação para o campo, desenvolvida com base em MINAYO (2014), constituiu-se da escrita de um projeto de pesquisa, em dezembro de 2015, da busca de financiamento e apoio, da seleção das cidades atingidas para pesquisa, dos locais das entrevistas nas cidades, do estabelecimento de critérios de amostragem, da escolha dos entrevistados e da estratégia de entrada em campo. A preocupação com os princípios éticos esteve presente, durante todo o desenvolvimento do estudo, procurando proteger os direitos dos indivíduos envolvidos. Nesse sentido, foram apresentados os propósitos da pesquisa e solicitada autorização para cada participante entrevistado, garantindolhes $\mathrm{o}$ anonimato $\mathrm{e} o$ direito de não participação.

Foram selecionadas nove cidades atingidas pela lama, por estarem ao longo da bacia do Rio Doce e por suspeita de estarem contaminadas por metais pesados. São elas: Aracruz, Regência, Linhares, Colatina e Baixo Guandu, no Estado do Espírito Santo, seguidas de Resplendor, Governador Valadares, Barra Longa e Bento Rodrigues, no Estado de Minas Gerais.

Trabalhou-se com uma população diversificada. Os critérios de amostragem foram estabelecidos com base em MINAYO
(2014), considerando que uma amostra ideal em pesquisa qualitativa não atende a critérios numéricos, mas é aquela que reflete as múltiplas dimensões da totalidade. Os critérios básicos, para constituição da amostra, foram os seguintes: seleção das pessoas atingidas com as características que os pesquisadores pretendiam conhecer; garantia de abrangência da diversidade do conjunto de informantes, no intuito de apreender semelhanças e diferenças; inclusão progressiva, conforme as descobertas de campo, e o confronto com a teoria. Procurou-se abranger vários ângulos da experiência das pessoas atingidas, nas cidades visitadas, que levassem à caracterização das percepções dessas da forma mais completa.

Para garantir a abrangência da diversidade da amostragem, foram contatadas lideranças políticas, lideranças do Movimento de Atingidos por Barragens (MAB), lideranças sindicais, associação de pescadores, grupo de bordadeiras, lideranças Indígenas do Território Indígena (TI) dos Guaranis, em Aracruz, e dos Krenak, em Resplendor, e profissionais da saúde dos locais selecionados. Essas lideranças compartilharam os contatos de pessoas atingidas de diferentes ramos, incluindo aquelas desprovidas de representação oficial, formando uma amostragem variada em gênero, classe e raça (etnia) da população atingida. 
Buscou-se assim, abordar o objeto de estudo de forma interseccional e ampla.

O trabalho de campo foi realizado no período de abril a junho de 2016. O envolvimento no campo assumiu variações, mas, em geral, as pessoas atingidas pareciam sentir-se aliviadas ao serem ouvidas por pesquisadores que buscavam levantar dados concretos sobre a contaminação de metais pesados. O tempo de cada entrevista variava muito dependendo da disponibilidade e disposição de cada entrevistado para falar sobre suas percepções e experiências.

As entrevistas eram, por vezes, previamente agendadas, dependendo da disponibilidade de cada entrevistado, e, em outras vezes, aconteciam de forma espontânea, sem agendamento. Também ocorriam quando e onde a pessoa entrevistada tivesse disponibilidade. Os pesquisadores se adequavam às disponibilidades dos entrevistados, mesmo se fosse necessário aguardar o momento em que tivessem tempo para conversar. Eram realizadas, em geral, nos locais de trabalho, em associações, residências de pessoas atingidas, nos assentamentos do Movimento dos Sem Terra (MST), em praças públicas, Unidades Básicas de Saúde (UBS), prefeituras, secretarias de saúde, dentre outros. No momento da entrevista, explicava-se a sua finalidade salientando que seu conteúdo seria acerca das percepções e experiências vividas pelo entrevistado, em decorrência do

\subsection{METAIS PESADOS}

No campo, as amostras dos sedimentos $(100 \mathrm{~g}$ até $1 \mathrm{~kg})$ foram coletadas em $1 \mathrm{~m}$ de profundidade das águas (rio, estuário, mar). A amostra da lama que, aparentemente, não foi tocada ou misturada desde a sedimentação, foi coletada debaixo de uma casa atingida em Barra Longa, Minas Gerais, por ser um local protegido da manipulação humana, da chuva ou da deposição aluvial. Todas as amostras sólidas foram guardadas em bolsas de polietileno tereftalato. As amostras das águas $(0,5 \mathrm{~L})$ foram coletadas na superfície (leito) e, em cima do sedimento, em $1 \mathrm{~m}$ de profundidade e armazenadas em garrafas de polietileno tereftalato, devidamente preparadas para coleta e, em seguida, etiquetadas, indicando a data, o local e o tipo de amostra. Todas as amostras foram guardadas em temperaturas adequadas para conservação e em lugar escuro, até a chegada ao laboratório. Dependendo do lugar da coleta, as amostras rompimento da barragem de Fundão. Todas as entrevistas foram realizadas com a utilização de gravador e, depois, transcritas.

Foram entrevistadas quarenta e duas pessoas atingidas: três indígenas da etnia Guarani, em Aracruz, sete pescadores (cinco de Regência, um pescador de Colatina e um ribeirinho de Governador Valadares), três pessoas atingidas do Movimento dos Sem Terra (MST), em Linhares, quatro bordadeiras (uma de Regência e três de Barra Longa), três mulheres profissionais da saúde (uma de Regência, uma de Governador Valadares e uma de Barra Longa), uma superintendente de saúde, um prefeito, cinco membros do Movimento de Atingidos por Barragens (MAB), quatro indígenas da etnia Krenak, de Resplendor, três pessoas atingidas de Regência, duas pessoas atingidas, em Governador Valadares, três pessoas atingidas, em Barra Longa, uma pessoa atingida, funcionário da Samarco Mineração S. A. e duas pessoas atingidas de Bento Rodrigues.

As entrevistas foram sistematizadas em uma tabela de Excel e classificadas por gênero, profissão, agrupamento ou etnia, número (se fosse mais do que uma pessoa na mesma classificação), local, ano da entrevista (2016) e principais eixos temáticos extraídos das transcrições. O prefeito, a superintendente de saúde, o funcionário da Samarco e os membros do MAB não foram classificados por localidade, para garantir o anonimato.

foram transportadas em, no máximo, uma semana, como em Regência e Aracruz, e, no mínimo, um dia, como em Barra Longa.

Chegando ao laboratório, as amostras das águas foram acidificadas com ácido nítrico (2 $\mathrm{ml} 65 \% \mathrm{HNO}_{3}$ em $500 \mathrm{ml}$ ), depois filtradas com filtros de celulose (CN-541, Quantitative) e colocadas na geladeira. Antes da leitura dos metais pesados totais (dissolvido e particular), as amostras foram filtradas em micropore $0,45 \mu \mathrm{m}$.

As amostras dos sedimentos e da lama foram secas à temperatura de $80^{\circ} \mathrm{C}$ e, em seguida, destorroadas com a utilização de um martelo de borracha. As amostras foram peneiradas para se obter a fração mais fina $(<0,063 \mathrm{~mm})$, utilizada para a análise química, depois pesadas e homogeneizadas. A metodologia utilizada para eluir os metais pesados, que são acessíveis no meio ambiente pelo processo do intemperismo, foi a digestão 
em micro-ondas com ácido nítrico concentrado, de acordo com a Agência de Proteção Ambiental dos Estados Unidos da América, método 3051-16, o qual segue descrito abaixo (MORAES; HORN, 2010, p. 81).

Pesou-se 0,5g de amostra em balança analítica, colocou-se em tubos de ensaio de Teflon, adicionou-se $10 \mathrm{~mL}$ de ácido nítrico concentrado e levou-se ao forno de micro-ondas MarsXpress da CEM por 25min. Deixou-se as amostras em repouso por $30 \mathrm{~min}$ para resfriamento e procedeu-se a transferência das mesmas para um balão volumétrico de $50 \mathrm{~mL}$, completando-se com água deionizada o volume dos mesmos. Após filtragem em micropore $0,45 \mu \mathrm{m}$ as soluções foram enviadas para a leitura (MORAES; HORN 2010, p. 81).

Nas amostras das águas, dos sedimentos e da lama, foram medidos os teores dos elementos alumínio $(\mathrm{Al})$, bário $(\mathrm{Ba})$, cádmio $(\mathrm{Cd})$, chumbo $(\mathrm{Pb})$, cobre $(\mathrm{Cu})$, cromo $(\mathrm{Cr})$ total, níquel $(\mathrm{Ni})$, zinco $(\mathrm{Zn})$, cobre $(\mathrm{Co})$, cálcio $(\mathrm{Ca})$ e magnésio $(\mathrm{Mg})(\mathrm{SM} 3120 \mathrm{~B}$ Inductively Coupled Plasma - Atomic Emission Spectroscopy), ferro (Fe) total e manganês (Mn) total (3111 B - Flame Atomic Absorption Spectrometry), arsênio (As) e selênio (Se) (SM 3114 C - Hydride Generation/Atomic Absorption Spectrometry)

\section{RESULTADOS E DISCUSSÃO}

\subsection{ENTREVISTAS}

As entrevistas semiestruturadas traduzem a representação das pessoas atingidas sobre sua percepção e experiência a respeito do rompimento da barragem de Fundão, no município de Mariana, Minas Gerais, em 5 de novembro de 2015. Dessa forma, as entrevistas constituem-se em uma aproximação entre o concreto vivido e o expressado em palavras. Considerando as limitações para sintetizar as vivências das pessoas atingidas, as entrevistas foram utilizadas para compor a relação entre as percepções e os dados obtidos por meio da análise do material coletado ao longo da bacia do Rio Doce.

Pescadores, durante as entrevistas, choravam ao contar sobre a morte dos milhares de peixes, por não saberem quanto tempo o rio levaria para se recuperar e por terem perdido seus meios de existência. Não sabiam se o Rio Doce estava contaminado com metais pesados, faltavam-lhes ainda diversos tipos de orientações. Havia uma diversidade de informações contraditórias sendo divulgadas e mercúrio (Hg) (SM 3112 B - Cold Vapor Atomic Absorption Spectrometry). $\mathrm{Hg}$ foi medido somente nas amostras das águas. As análises químicas foram realizadas no laboratório do Núcleo de Pesquisa em Geoquímica Ambiental do Centro de Pesquisas Professor Manoel Teixeira da Costa do Instituto de Geociências / Universidade Federal de Minas Gerais (IGC/UFMG) (SM 3120 B, modelo M4165-Espectroflame-Spectro) e no laboratório da Divisão de Pesquisa e Controle de Qualidade de Águas e Esgoto (DVQA) da Companhia de Saneamento de Minas Gerais (COPASA) (SM 3120 B, SM 3111 B, SM 3114 C, SM 3112 B). Em ambos os laboratórios, foram analisadas as mesmas amostras.

As concentrações medidas foram comparadas com valores de referência, como padrões de qualidade e regional backgrounds (concentrações regionais). O termo regional backgrounds é usado neste estudo para denominar a concentração de metais pesados existentes nos solos da região da bacia do Rio Doce, antes do rompimento da barragem de Fundão ou solos dessa região que estão fora do alcance da lama.

em veículos de comunicação e eles não sabiam em qual fonte confiar.

Esse Rio Doce aí morto, morto, tá morto pá nós. [...] Me criei, criei meus seis filhos tirado dali, eu e minha mulher trabalhando. [...] Ele (o Rio doce) é vivo igual nós. Ele tá $[\ldots]$ pedindo o que? Socorro! Ele tá jogado aí e não tem uma pessoa pá cuidá dele. [...] E vê essa situação. Eu sinto. Eu me emociono (soluços e lágrimas). (Pescador 1, Regência, 2016).

Aqui tão chegando peixes mortos. [...] Também tem uma carapuça de lama em volta das conchas, olha aqui (mostraram a concha e a pele de lama em volta dela). A gente não sabe se pode ou não comer os peixes e mariscos agora. Você comeria? (Homem da etnia Guarani 1, Aracruz, 2016).

Além de perder renda e os meios de produção, dezenas de pescadores não receberam o "cartão da Samarco" e tiveram que se mudar para assentamentos do Movimento dos Sem Terra (MST) próximo a Linhares. Idosos, crianças e famílias inteiras viviam em barracas de lona com infraestrutura precária, contando apenas com um barracão, um pouco de água encanada e um banheiro. 
Outro grupo, em situação de desinformação quanto aos metais pesados, era o dos indígenas da etnia Krenak, em Resplendor, Minas Gerais.

Esse metal pesado que tem no rio (Rio Doce) hoje, nos impede de realizar aquilo que é da nossa cultura. Isso é triste. [...] Se fala da recuperação do rio a longo prazo, uns falam de cinquenta anos, outros falam de cem anos. A gente tem esperança de um dia poder pescar, nadar e ensinar nossas crianças a nadar no rio (Homem da etnia Krenak 3, Resplendor, 2016).

Esse grupo dependia do rio para sua sobrevivência e, também, como parte de seus rituais sagrados. Diante daquele cenário, emergiam diversas dúvidas existenciais, uma vez que não sabiam quanto tempo levaria para voltarem às atividades pesqueiras para sobrevivência, para consumirem a água e para nadarem. Os quadros de dermatoses infantis e queda de cabelo compunham o elenco de doenças que apareceram com a chegada da lama (Mulher da etnia Krenak 2, Resplendor, 2016).

Meu irmão é pescador e ficou desesperado. [...] o rio (Rio Doce) ficou coalhadinho de peixe morto. [...] É o rio que eles (meus filhos) aprenderam a nadar. Agora nossos filhos, nossos netos, vão aprender a nadar em que rio? (Mulher da etnia Krenak 2, Resplendor, 2016).

Após o rompimento da barragem de Fundão, a comunidade dos indígenas da etnia Krenak passou a receber água engarrafadas trazidas por caminhões da prefeitura. As garrafas PET acumulavam-se em seus territórios e poluíam o ambiente. O que se via, com a chegada da lama, era um rio de águas vermelhas, coalhado de peixes mortos, aparentando, para as populações ribeirinhas, que tudo estava perdido, que levaria, possivelmente, séculos para o Rio Doce se recuperar novamente. Os pescadores e os indígenas Krenaks falavam do Rio Doce como se ele fosse ser vivo, como se estivesse doente e precisando de cuidados.

O povo tá desconfiado. Tô com 106 anos e nunca aconteceu isso que está acontecendo agora. [...] (Cantaram uma canção em homenagem ao Rio Doce e foi um momento de muita emoção entre eles). (Homem da etnia Krenak 1, Resplendor, 2016)

A falta de informações causava grande desespero entre as pessoas atingidas que viviam ao longo da bacia do Rio Doce. Não sabiam se poderiam pescar, nadar ou fazer qualquer uso da água do Rio Doce. As pessoas atingidas tinham dificuldades para conseguir água potável. Esse foi um tema comum em todas as entrevistas. Elas tinham medo e inseguranças quanto ao futuro.

Com a chegada desordenada da lama, as bordadeiras de Barra Longa, Minas Gerais, perderam toda a produção, o material para $o$ bordado e os equipamentos de trabalho (Bordadeiras 2 e 3, Barra Longa, 2016). Algumas delas não foram consideradas como atingidas e não receberam o cartão da Samarco, que poderia significar a esperança de recuperação da perda, e, assim, elas tiveram que se mudar para casa de familiares e amigos (ibid.). A bordadeira de Regência, Espírito Santo, também não foi considerada como atingida e, como à cidade não vinham mais turistas para comprar seus bordados, portanto, ela ficou só com uma pensão do falecido esposo para viver, tendo sua renda diminuída pela metade (Bordadeira 1, Regência, 2016). Ela também, em lágrimas, contava sobre a dificuldade financeira em que se encontrava.

As pessoas atingidas no distrito de Bento Rodrigues, Gesteira e Paracatu de Baixo foram realocadas em outros municípios, especialmente em Mariana e continuam vivendo em casas alugadas (FREITAS et al., 2019).

As pessoas atingidas de Bento Rodrigues encontravam-se em um processo de negociação na busca de um outro terreno para a reconstrução de suas casas, em um "novo" Bento Rodrigues (Pessoas atingidas 1, 2 e 3, Bento Rodrigues, 2016). Essas pessoas declararam profunda tristeza pela perda de seus familiares, ou mesmo perda total de seus pertences, álbuns fotográficos, casas, enfim tudo que tinham (ibid.). Elas não utilizavam a classificação do rompimento da barragem de fundão como "desastre" e sim como "crime" (ibid.). Tinham dificuldade de adaptação na cidade de Mariana e relatavam que eram discriminadas por buscar indenizações perante a Samarco Mineração S.A. e o município. Eram culpadas de "atrapalhar" assim a possibilidade de reabertura da empresa, levando a grandes impactos na economia (ibid.). Mariana é um município cuja receita depende $80 \%$ da mineração (FREITAS et al., 2019). Essa dependência atinge as receitas arrecadadas e reflete na cadeia econômica levando a um declínio sistêmico da economia local (ibid.). Dessa forma, desenvolve-se uma relação ambígua de sentimento de repúdio e traição com relação às empresas envolvidas e a dependência econômica das pessoas e municípios que demandam a continuação das atividades da empresa. 
As pessoas de Bento Rodrigues viviam um trauma contínuo, com pouca assistência psicológica (Pessoas atingidas 1, 2 e 3, Bento Rodrigues, 2016). Relatavam principalmente de doenças psíquicas sofridas por elas mesmas e por seus familiares, expressavam a sensação de impotência e a falta de perspectiva para o futuro (ibid.).

Um trabalhador da Samarco Mineração S. A. contou que quase não sobreviveu e estava com dificuldades para conseguir indenização da empresa, pois era um funcionário terceirizado com menos direitos trabalhistas (trabalhador da Samarco Mineração S. A., 2016).

Os pescadores, os ribeirinhos, as bordadeiras, os indígenas da etnia Krenak, as lideranças do MAB (Movimento dos Atingidos

\subsection{METAIS PESADOS NAS ÁGUAS}

Somente as concentrações de $\mathrm{Al}, \mathrm{Fe}$ e $\mathrm{Mn}$ excedem os padrões do Conselho Nacional do Meio Ambiente (CONAMA 2009) para rios de classe II (Tabela 1). As concentrações nas amostras colhidas do fundo do Rio Doce foram mais altas do que as da superfície. Próximo ao sedimento, as maiores concentrações de $\mathrm{Al}, \mathrm{Fe}$ e $\mathrm{Mn}$ foram encontradas nas amostras de Governador Valadares pelos dois laboratórios participantes, com valores até 11,14 ou 67 vezes superiores aos valores-limite do CONAMA (ibid.). Na superfície da água, nas amostras de Barra Longa, analisadas por ambos os laboratórios, foram encontradas as maiores concentrações de $\mathrm{Fe}$ e $\mathrm{Mn}$, excedendo os valores-limite do CONAMA em até 2 e 1,5 vezes, respectivamente (ibid.).

A explicação parece estar na composição das amostras e no tratamento das mesmas.

\subsection{METAIS PESADOS NA LAMA}

Os resultados da análise da lama foram comparados com diferentes valores de referência dos estudos BALTAZAR e RAPOSO (1993) e SEGURA et al. (2016). Como demonstrado na figura 2 , de todos os metais pesados analisados na lama, somente o Ferro excedeu significativamente os regional backgrounds na região de Mariana. Os regional backgrounds dos estudos BALTAZAR e RAPOSO (1993) e SEGURA et al. (2016) são, respectivamente, os valores de $\mathrm{As}, \mathrm{Pb}, \mathrm{Co}, \mathrm{Cu}, \mathrm{Cr}, \mathrm{Fe}, \mathrm{Mn}, \mathrm{Ni}$ e $\mathrm{Zn}$ para os sedimentos em águas correntes, em Mariana (BALTAZAR; RAPOSO, 1993) e os valores por Barragens) e os profissionais da Atenção Básica de Saúde explicaram nas entrevistas (2016) que estavam sofrendo diversos tipos de perdas e de adoecimentos. As perdas eram desde entes queridos até materiais, como a perda de suas casas, perdas econômicas e dos recursos de renda. As doenças variavam entre dermatoses, irritações oculares, diarreias, doenças respiratórias entre as pessoas que viviam próximas ao Rio Doce ou perto da poeira da lama. Havia também adoecimentos psíquicos, com casos de surtos, depressões e três casos de tentativas de autoextermínio. A questão da saúde era trazida por todas as pessoas entrevistadas. A saúde das pessoas atingidas parece ser um campo ainda carente de evidências científicas (FREITAS et al., 2019)

Analisou-se a quantidade total que consiste em metais que estão conectados às partículas e em metais que estão dissolvidos. No fundo, foram encontradas mais partículas na água.

As concentrações dos outros metais pesados medidos não excedem os limites da quantificação. Os resultados das águas estão em conformidade com o estudo de GIAIA (2016). IGAM e SEMAD (2017) encontraram em 2016 concentrações mais altas do que os resultados deste estudo, tanto para $\mathrm{Al}, \mathrm{Fe}$ e $\mathrm{Mn}$, quanto para os outros metais pesados $(\mathrm{Cu}, \mathrm{Pb}$, $\mathrm{Cr}, \mathrm{Cd}, \mathrm{Ni}$ ). Numa segunda investigação no ano seguinte, em 2017, as concentrações encontradas por IGAM e SEMAD (2017) diminuíram, permanecendo quase todas abaixo dos padrões da CONAMA (2009).

de $\mathrm{Al}$ e $\mathrm{Cd}$, para solos, em Bento Rodrigues (SEGURA et al., 2016).

A figura 2 mostra que os resultados da análise da lama estão em conformidade com os resultados do estudo da SEGURA et al. (2016), que utilizou a mesma metodologia analítica. As amostras de lama de Barra Longa tiveram quantidades de metais pesados mais elevados do que a lama de Bento Rodrigues, do estudo citado, provavelmente porque a lama se misturou com solos e sedimentos no caminho. A quantidade de metais pesados na lama é mais baixa do que os valores de referência de qualidade dos solos (CETESB, 2005). 


\subsection{METAIS PESADOS NOS SEDIMENTOS}

Os resultados da análise mostraram que a quantidade de metais pesados encontrados nos sedimentos misturados com a lama é maior do que os valores encontrados na lama pura. No Rio Doce, eles estão significativamente mais altos do que os valores dos regional backgrounds (BALTAZAR; RAPOSO, 1993;
SEGURA et al., 2016), com exceção do Níquel e Cobalto (Tabela 2). Nos sedimentos do Rio Doce, alguns metais pesados excedem os valores de referência de qualidade, mas não os valores de prevenção (CETESB, 2005), com exceção de Cobre em Resplendor.

Tabela 1 - Concentrações de Al, Fe e Mn em águas da bacia do Rio Doce da superfície e do fundo em abril de 2016, medidas no Instituto de Geociências/ Universidade Federal de Minas Gerais (IGC/UFMG) e na Companhia de Saneamento de Minas Gerais (COPASA), em comparação com padrões do Conselho Nacional do Meio Ambiente (CONAMA) para rios da classe II (* valores maiores do que os padrões).

\begin{tabular}{|c|c|c|c|c|c|c|}
\hline $\begin{array}{l}\text { Concentração } \\
(\mathrm{mg} / \mathrm{L})\end{array}$ & $\begin{array}{c}\text { Al } \\
\text { (IGC/UFMG) }\end{array}$ & $\begin{array}{c}\text { Al } \\
(\text { COPASA })\end{array}$ & $\begin{array}{c}\text { Fe } \\
\text { (IGC/UFMG) }\end{array}$ & $\begin{array}{c}\text { Fe } \\
(\text { COPASA })\end{array}$ & $\begin{array}{c}\text { Mn } \\
\text { (IGC/UFMG) }\end{array}$ & $\begin{array}{c}\text { Mn } \\
\text { (COPASA) }\end{array}$ \\
\hline \multicolumn{7}{|l|}{ Fundo: } \\
\hline Barra Longa & 0,01 & 0,10 & 0,25 & $0,40 *$ & $0,13 *$ & $0,14^{*}$ \\
\hline Governador Valadares & $1,04 *$ & $1,11^{*}$ & $4,27 *$ & $3,56^{*}$ & $6,74^{*}$ & $5,18^{*}$ \\
\hline Resplendor & $0,23 *$ & $0,33 *$ & $0,38 *$ & $0,51 *$ & $0,45^{*}$ & $0,37 *$ \\
\hline Colatina & $0,40 *$ & $0,75^{*}$ & $0,82 *$ & $0,85^{*}$ & $2,14^{*}$ & $1,02 *$ \\
\hline Regência & $0,56^{*}$ & $0,34 *$ & $0,73 *$ & $0,61 *$ & $0,18^{*}$ & $0,12 *$ \\
\hline Aracruz & $0,40 *$ & $0,15^{*}$ & 0,30 & $0,37 *$ & $0,15^{*}$ & $<0,1$ \\
\hline \multicolumn{7}{|l|}{ Superfície: } \\
\hline Barra Longa & 0,04 & 0,10 & $0,61 *$ & $0,68^{*}$ & $0,14^{*}$ & $0,16^{*}$ \\
\hline Governador Valadares & $<0,008$ & 0,08 & 0,19 & $0,35^{*}$ & 0,05 & $<0,1$ \\
\hline Resplendor & 0,05 & $0,11 *$ & 0,16 & 0,29 & 0,02 & $<0,1$ \\
\hline Colatina & $<0,008$ & 0,10 & 0,06 & $0,46^{*}$ & $<0,006$ & $<0,1$ \\
\hline Regência & 0,05 & 0,09 & 0,15 & 0,29 & $<0,006$ & $<0,1$ \\
\hline Aracruz & $0,30 *$ & $<0,05$ & 0,07 & 0,16 & $0,13 *$ & $<0,1$ \\
\hline $\begin{array}{l}\text { Padrão (CONAMA, } \\
\text { Rio Classe II) }\end{array}$ & 0,10 & 0,10 & 0,30 & 0,30 & 0,10 & 0,10 \\
\hline
\end{tabular}

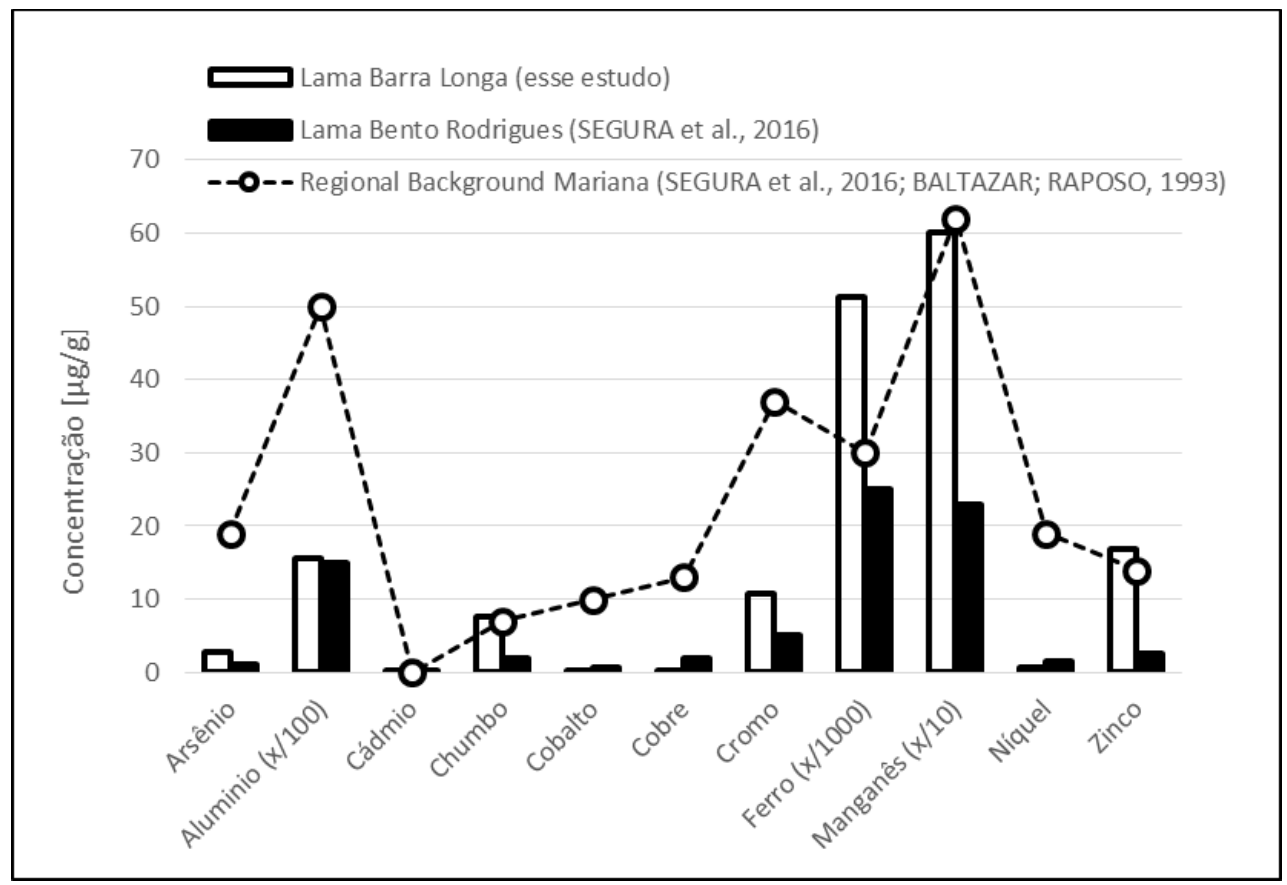

Figura 2

Os metais pesados na lama e os regional backgrounds da região de Mariana (os valores de $\mathrm{Al}$, Fe e Mn são respectivamente divididos por 100, 1000 e 10, como o valor do Fe na lama de Barra Longa é 51.000 mg/g). 
Tabela 2 - Concentrações de metais pesados nos sedimentos da bacia do Rio Doce em abril de 2016, em comparação com backgrounds regionais e padrões de qualidade (* valores maiores do que os regional backgrounds ** valores maiores do que o Valor de Prevenção - CETESB, 2005).

\begin{tabular}{|c|c|c|c|c|c|c|c|c|c|}
\hline $\begin{array}{l}\text { Concentração } \\
(\mathrm{mg} / \mathrm{kg})\end{array}$ & Al & $\mathbf{F e}$ & Mn & $\mathrm{Cu}$ & $\mathrm{Cr}$ & $\mathbf{N i}$ & $\mathbf{P b}$ & Co & $\mathbf{Z n}$ \\
\hline Barra Longa & 600 & $26.680 *$ & 172 & 0,04 & 0,43 & 0,60 & 3,74 & 0,18 & $10,30 *$ \\
\hline Governador & $11.790 *$ & $58.000 *$ & $855^{*}$ & 11,09 & $46,67 *$ & 4,37 & $25,05^{*}$ & 2,50 & $91,30 *$ \\
\hline Resplendor & $21.350^{*}$ & $100.500 *$ & $1.280 *$ & $81,50 * *$ & $67,30 *$ & 9,98 & $39,80 *$ & 7,36 & $75,70^{*}$ \\
\hline Colatina & $21.920 *$ & $89.100 *$ & $1.168 *$ & $21,91 *$ & $68,60 *$ & 12,23 & $33,02 *$ & 8,67 & $80,60 *$ \\
\hline Aracruz & $21.750 *$ & $47.750 *$ & 359 & 14,95 & $45,48^{*}$ & 2,89 & $23,21 *$ & 0,38 & $103,40^{*}$ \\
\hline $\mathrm{VRQ}^{1}$ & - & - & - & 35 & 40 & 13 & 17 & 13 & 60 \\
\hline $\mathrm{VP}^{2}$ & - & - & - & 60 & 75 & 30 & 72 & 24 & 300 \\
\hline $\mathrm{RB} \mathrm{B}^{3}$ & 5.000 & 17.000 & 420 & 5,5 & 20 & 6 & 7 & 2,5 & 7,5 \\
\hline $\mathrm{RB} \mathrm{M}^{4}$ & No data & 30.000 & 620 & 13 & 37 & 19 & 7 & 10 & 14 \\
\hline $\mathrm{RB} \mathrm{C}^{5}$ & No data & No data & 613 & 15 & 33 & 21 & 14,5 & 18 & 60 \\
\hline
\end{tabular}

1 Valor de referência de qualidade (CETESB, 2005)

2 Valor de Prevenção (CETESB, 2005)

3 Regional Background (port.: concentração regional) - Bento Rodrigues (SEGURA et al., 2016)

4 Regional Background - Mariana (1985-89) (BALTAZAR; RAPOSO, 1993)

5 Regional Background - Colatina (1985-89) (TULLER, 1993)

\section{CONCLUSÕES}

Este estudo mostrou que a concentração de metais pesados na lama originária do rompimento da barragem de Fundão, próxima a Bento Rodrigues, município de Mariana, Minas Gerais, em 5 de novembro de 2015, está no mesmo nível ou abaixo da concentração de metais pesados nos solos e sedimentos da região (regional backgrounds), com excessão do ferro $(\mathrm{Fe})$. Como a concentração de metais pesados nos sedimentos atingidos da bacia do Rio Doce está mais elevada do que a concentração na lama e do que os valores dos regional backgrounds, supõe-se que os metais pesados dos sedimentos não sejam de origem da lama, e, sim, de outras fontes, provavelmente antrópicas, como indústria, agricultura, mineração, gestão de energia, habitação, entre outras. A lama, no entanto, contribuiu para o aumento de ferro nos sedimentos e solos da bacia do Rio Doce, mas não elevou a concentração dos demais metais pesados nos sedimentos e solos.

O aumento da concentração de metais pesados na água, após a ruptura da barragem de Fundão, superior aos valores-limites, foi observado neste estudo ( $\mathrm{Al}, \mathrm{Fe}, \mathrm{Mn}$ ), bem como no estudo de IGAM e SEMAD (2017) (Al, $\mathrm{Fe}, \mathrm{Mn}, \mathrm{Cu}, \mathrm{Pb}, \mathrm{Cr}, \mathrm{Cd}, \mathrm{Ni}$ ). Esse aumento não foi causado pela composição química da lama, mas, provavelmente, pela força física dela, ao agitar os sedimentos. Essa agitação pode ter provocado a relocação e a liberação de metais pesados já existentes, que tinham sido absorvidos pelos sedimentos do Rio Doce antes do rompimento. A contaminação da água pelos metais pesados, superior aos valoreslimites, parece designar uma condição provisória, pois, no ano seguinte, em 2017, segundo IGAM e SEMAD (2017), a concentração de metais pesados na água diminuiu, voltando a ser inferior aos valoreslimites. Os metais pesados devem ter sido relocados, ou então, reabsorvidos pelo sedimento.

A concentração de metais pesados nos sedimentos da bacia do Rio Doce encontrou-se elevada em relação aos valores dos regional backgrounds. Considera-se, entretanto, que os sedimentos, na definição da CETESB (2005), não são classificados como "limpos", mas ainda "capazes de sustentar suas funções primárias" (CETESB, 2005). No caso da concentração do cobre, em Resplendor, "podem ocorrer alterações prejudiciais à qualidade do solo e da água subterrânea" (ibid.). Eventos físicos que agitem o sedimento (como chuva forte) podem proporcionar a liberação dos metais pesados na água. Além disso, os metais pesados absorvidos pelos sedimentos e solos, podem ser liberados pelos processos bioquímicos e acumulados nas plantas e microorganismos, entrando assim para a cadeia alimentar. Com isso, a longo prazo, a saúde humana e o meio ambiente são colocados em risco. Recomenda-se a observação do desenvolvimento das concentrações dos metais pesados nos constituintes do Rio Doce (flora, fauna, água e sedimento).

Os danos mais graves da lama parecem não ser de natureza química e, sim, física, como a cobertura de muitos hectares de sedimentos e solos, causando mortes, devastação do ambiente (fauna e flora) e destruição de 
propriedades privadas. As partículas de lama são muito finas (1 a $200 \mu \mathrm{m})$ (SEGURA et al., 2016). Essa característica aumenta a opacidade da água após a agitação dos sedimentos e pode acarretar a devastação de habitats, numa micro e mesoescala, a extinção de espécies e a diminuição da biodiversidade. A mistura da lama com os solos modifica a composição dos mesmos, diminuindo a fertilidade e a permeabilidade e, com isso, a qualidade. As partículas de lama seca podem ser facilmente deslocadas pelo vento e podem gerar doenças respiratórias e dermatológicas. Portanto, além dos metais pesados, é preciso pensar na sustentabilidade de uma maneira geral ao refletir sobre questões antropogênicas.

Conclui-se que a lama da barragem de Fundão causou mortes, perdas materiais, doenças físicas e psíquicas, bem como elevou a concentração de ferro nos sedimentos e solos e, devido a sua força física, liberou, provisoriamente, outros metais pesados que já existiam nos sedimentos, contaminando a água do Rio Doce. A lama danificou sedimentos, solos, promoveu a contaminação da água e devastou o meio ambiente.

As entrevistas evidenciaram um panorama de desinformação das pessoas atingidas pelo rompimento da barragem de Fundão. As pessoas se sentiam impotentes em relação ao acontecido e não sabiam quanto tempo demoraria para que pudessem voltar às suas atividades normais, serem indenizadas, reaverem suas perdas materiais, formas de renda, utilizar o Rio Doce novamente ou mesmo, as que ainda tivessem casa, quando poderiam voltar às mesmas. As pessoas atingidas expressavam as angústias e as diferentes formas de adoecimento físico e psíquico. Elas demonstravam indignação com as empresas e governos envolvidos e, ao mesmo tempo, dependiam economicamente dessas empresas.

Considerando o ocorrido, conclui-se também que as pessoas atingidas devem ser informadas sobre a contaminação de metais pesados nos rios, solos, sedimentos e sobre a mudança da concentração desses metais ao longo dos anos. Elas precisam ser informadas sobre as prováveis consequências para suas vidas devido à corrência da lama, como as doenças respiratórias e dermatológicas, bem como as consequências para o meio ambiente, como o possível acúmulo de metais pesados na cadeia alimentar.

A exploração do minério ainda não é feita de forma sustentável para o meio ambiente e segura para as pessoas. Os superávits comerciais em favor dos países do norte pendem para o lado deles e o tipo de exportação também explicita uma diferença qualitativa, enquanto o Brasil exporta "matérias-primas não processadas (ou pouco processadas), como minério de ferro, placas de aço ou soja, de menor valor, a Alemanha exporta bens de capital, como máquinas, ou industrializados, como produtos químicos e farmacêuticos" (DILGER; KRAWINKEL, 2017). Essa assimetria está alicerçada em um sistema econômico mundial, cujas raízes históricas remetem à exploração colonial, que hoje foi sucedida por uma dependência neocolonial dos países do Sul, com suas riquezas em recursos naturais exploradas pelos grandes centros industriais (ibid.). Se não houver mudança na mentalidade extrativista, a exploração de pessoas e da natureza em nível global, baseada na desigualdade e na destruição ambiental, seguirá causando crises e desastres ("crimes") socioambientais.

No desenvolvimento neoliberal, o capital constitui o centro do extrativismo, restringindo as questões socioambientais à margem do processo ou mesmo à desconsideração total. Um prefeito resume esse raciocínio da seguinte maneira:

"Nós nos diminuímos frente ao capital. Nós trabalhamos muito, quase não temos tempo para nossos filhos e família. E quando acontece uma coisa igual a essa a culpa também é nossa. O que é que estamos fazendo para evitar isso? Se o capital é a coisa mais importante, não podemos nos queixar de que a justiça agiu mal, o governo agiu mal. Os diretores e empregados dessas empresas talvez não saibam, mas eles não têm nenhuma importância. O importante é o capital. Donos entram e saem, diretores entram e saem, funcionários entram e saem. Quem morreu lá em cima, dos 19, parece que só 1 ou 2 eram empregados regularmente pela Samarco, os outros eram terceirizados, ou seja funcionários precários, sem direitos trabalhistas. Enfim é uma miscelânea de questões que emergem dessa lama que precisamos refletir. O mundo está indo para um abismo e tem pouca gente querendo frear. Tem condição de melhorar, mas como fazer?" (Prefeito, 2016).

Essas palavras sumarizam a condução atual da extração de minérios no Brasil. Ela evidencia a falta de planejamento sustentável das empresas mineradoras, bem como a flexibilidade do controle governamental no processo de exploração. Nesse raciocínio, essas partes responsáveis tendem a marginalizar ou desconsiderar as populações atingidas e o meio ambiente.

Diante de um panorama de mortes e adoecimentos em decorrência da lama, uma 
superintendente regional da saúde releva que "precisamos ter empresas mais conscientes, aplicando de fato a sustentabilidade, o desenvolvimento sustentável, para garantir às pessoas, que estão vulneráveis, maior segurança" (Superintendente Regional da Saúde, 2016).

Supunha-se que, depois de um acontecimento como a ruptura da barragem de Fundão, as empresas envolvidas e os governos tivessem avançado nas formas de evitar esse tipo de acontecimento. No entanto, em janeiro de 2019, houve uma nova ruptura de barragem em Minas Gerais, o que demonstra que pouco ou nada foi aprimorado desde a primeira experiência. Consideramos ser necessária a realização de estudos no caso da ruptura da barragem do Córrego do Feijão, em Brumadinho, Minas Gerais. Segundo a Vale, vazaram 12 milhões de metros cúbicos de rejeitos em Brumadinho. Em Mariana, há 4 anos, foram 43,7 milhões (G1 GLOBO 25.01.2019). Em Brumadinho a lama deixou 253 mortos e 17 desaparecidos até o momento (FOLHA DE SÃO PAULO 13.11.2019). Suspeita-se que a lama de Brumadinho tenha atingido o Rio São Francisco (G1 GLOBO 29.03.2019).

No Brasil, há 769 barragens de mineração, e a extração de minério constitui uma das principais bases econômicas para centenas de municípios (FREITAS et al., 2019). Nessa constelação de dependência da extração mineral, propõe-se o fomento de projetos governamentais que incitem um desenvolvimento com o objetivo de reduzir a dependência econômica desses municípios das empresas mineradoras e que implementem a sustentabilidade ambiental e a justiça social.

As rupturas das barragens de Fundão e do Córrego do Feijão em Minas Gerais são consideradas como os mais graves "desastres" no país e no mundo e, no entanto, foram classificadas, antes do acontecimento, como barragens de baixo risco (FREITAS et al., 2019). As rupturas trouxeram experiências traumatizantes e dolorosas para a população e, ao mesmo tempo, lições fundamentais sobre formas destrutivas de exploração socioambiental.

A classificação do rompimento da barragem de Fundão como "desastre" é polêmica entre as pessoas atingidas que preferem utilizar o termo "crime" socioambiental. O planejamento da gestão ambiental, do extrativismo e da construção das barragens deve envolver um efetivo e transparente processo intersetorial de planificação, com a participação das empresas, do poder público, da sociedade civil organizada, do MAB, do SUS (Sistema Único de Saúde), da Defesa Civil e de outros órgãos, podendo-se considerar o Marco de Sendai para a Redução de riscos de Desastres 2015-2030. Esse Marco fomenta o trabalho articulado, intersetorial para as questões de desastres naturais, tecnológicos e emergências em saúde pública. Mesmo que o rompimento de Fundão não seja considerado um desastre natural, esse processo intersetorial pode ajudar a preparar os municípios para atuarem no planejamento, na prevenção e em casos de emergência. Isso evitaria possivelmente situações como as vivenciadas em 2019, no município de Barão de Cocais, onde sirenes tocaram e famílias foram imediatamente removidas de suas casas, deixando suas propriedades inseguras, desconsiderando os estresses e temores desencadeados, causando possíveis reflexos negativos na saúde da comunidade (FREITAS et al., 2019).

Nas últimas décadas, estudos têm demonstrado a importância da sustentabilidade ambiental (SOUZA; RIBEIRO, 2013; NASCIMENTO, 2012). Em tempos de sustentabilidade e de ganho de consciência sobre o meio ambiente e as questões sociais, a responsabilidade socioambiental corporativa, bem como a reputação das empresas ganham relevância e faz-se necessário exercer pressão sobre as empresas para que elas mudem sua mentalidade extrativista com base no capital e transformem sua atuação para com os países do Sul (DILGER; KRAWINKEL, 2017).

Em face dos dois rompimentos de barragens, o desenvolvimento sustentável e o planejamento intersetorial precisam ser concretizados e implementados em caráter de urgência. Essa implementação deve ser feita em empresas privadas, em empresas públicas e deve ser controlado pelos governos e demais setores, para evitar a violação de direitos e a destruição ambiental. Este estudo demonstra a necessidade de que essas partes realizem uma exploração mais sustentável, diversificada e participativa do que a exercida até então, de que se executem projetos para prevenir rompimentos de barragens e, em caso de nova ocorrência, que desenvolvam planos emergenciais, alertas e alarmes que garantam a segurança das populações e dos trabalhadores. É preciso diversificar a economia dos municípios que hoje dependem da mineração. $\mathrm{O}$ investimento na pesquisa, na sustentabilidade para o extrativismo, na 
diversificação econômica, na formação de profissionais, que atuem em casos de desastres, preconiza assegurar a sobrevivência do planeta

\section{AGRADECIMENTOS}

Os autores agradecem pelo financiamento e apoio ao FDCL (Centro Latino-americano de

\section{REFERÊNCIAS}

BALTAZAR, O. F.; RAPOSO, F. O. (Orgs.). Mariana: folha SF.23-X-B-I: estado de Minas Gerais. Brasília: DNPM. CPRM. Programa de Levantamentos Geológicos Básicos do BrasilPLGB. Escala 1:100.000. 1993. Disponível em: http://rigeo.cprm.gov.br/xmlui/handle/doc/8634. Acesso em 08 dez 2019.

BARDIN, L. Análise de conteúdo. Lisboa: Edições 70, 1979. 230p.

CETESB (COMPANHIA DE TECNOLOGIA DE SANEAMENTO AMBIENTAL). Valores Orientados para Solos e Águas... Decisão de diretoria $\mathrm{N}^{\circ}$ 195-2005-E, de 23 de novembro de 2005, São Paulo, 4 p. 2005. Disponível em: https://cetesb.sp.gov.br/solo/wpcontent/uploads/sites/18/2014/12/tabela_valores 2005.pdf Acesso em 08 dez 2019.

CONAMA (CONSELHO NACIONAL DE MEIO AMBIENTE). Conselho Nacional do Melo Ambiente - Resolução CONAMA no 420, de 28 de dezembro de 2009. Brasília: Ministério do Meio Ambiente, 2009. p. 81-84. Disponível em: http://www2.mma.gov.br/port/conama/legiabre. cfm?codlegi=620. Acesso em $08 \mathrm{dez} 2019$.

DILGER, G.; KRAWINKEL, M. Apresentação. In: RUSSAU, C. (Ed.). Empresas Alemãs no Brasil. São Paulo: Elefante, 2017. p. 11-15.

EPA (ENVIROMENTAL PROTECTION AGENCY). 2007. Method 3051, A Microwave assisted acid digestion of sediments, sludges, soils and oils - revision 1, Washington D.C., 30 p. Disponível em: https://www.epa.gov/sites/production/files/2015 -12/documents/3051a.pdf. Acesso em 09.12.2019.

FOLHA DE SÃO PAULO. Identificada $253^{a}$ vítima da tragédia de Brumadinho (MG). 2019. Disponível em: https://www1.folha.uol.com.br/cotidiano/2019/1 1/identificada-253a-vitima-da-tragedia-debrumadinho-mg.shtml. Acesso em 13 nov. 2019.

FREITAS, C. M. et al. DA Samarco em Mariana à Vale em Brumadinho: desastres em barragens de mineração e Saúde Coletiva. Cadernos de Saúde Pública, v. 35, n. 5, Rio de Janeiro. Maio. $2019 . \quad$ Disponível em: http://www.scielo.br/scielo.php?script=sci_artte $\mathrm{xt} \& \mathrm{nrm}=\mathrm{iso} \& \operatorname{lng}=\mathrm{pt} \&$ tlng $=$ pt\&pid $=\mathrm{S} 0102-$ 311X2019000600502\#B6. Acesso em 09.12.2019. e das futuras gerações. Essas noções devem ser efetuadas e não mais postergadas em prol do capital.

Pesquisa e Documentação em Berlim), à COPASA e ao IGC/UFMG.

G1 (GLOBO). Barragem da Vale se rompe em Brumadinho, MG. 2019. Disponível em: https://g1.globo.com/mg/minasgerais/noticia/2019/01/25/bombeiros-e-defesacivil-sao-mobilizados-para-chamada-derompimento-de-barragem-em-brumadinho-nagrande-bh.ghtml. Acesso em 25 jan. 2019.

G1 (GLOBO). Rejeitos de Brumadinho chegaram ao Rio São Francisco, diz Fundação Joaquim Nabuco. 2019. Disponível em: https://g1.globo.com/pe/pernambuco/noticia/201 9/03/29/rejeitos-de-brumadinho-chegaram-aorio-sao-francisco-diz-fundacao-joaquimnabuco.ghtml. Acesso em 29 mar 2019.

GIAIA (GRUPO INDEPENDENTE DE AVALIAÇÃO DO IMPACTO AMBIENTAL). 2016. Relatório-técnico: Determinação de metais na bacia do rio Doce (período: dez-2015 a abril-2016). Disponível em: http://giaia.eco.br/wpcontent/uploads/2016/06/RelatorioGIAIA_Metais_Vivian_revisto5.pdf. Acesso em 21 nov. 2018.

IGAM (INSTITUTO MINEIRO DE GESTÃO DAS ÁGUAS); SEMAD (SECRETARIA DE ESTADO DO MEIO AMBIENTE E DESENVOLVIMENTO SUSTENTÁVEL). 2017. Encarte especial sobre a qualidade das águas do rio Doce após 2 anos do rompimento de barragem de Fundão 2015-1017. Belo Horizonte, $31 \mathrm{p}$.

MINAYO, M. Técnicas de Análise de Material Qualitativo. In: MINAYO, M. (Ed.). Desafio do Conhecimento: Pesquisa Qualitativa em Saúde. 14. ed. São Paulo: Hucitec, 2014. p. 303360.

MORAES, P. P. F.; HORN, A. H. Teores dos metais pesados $\mathrm{Cr}, \mathrm{Cd}$ e $\mathrm{Zn}$ em perfis de solos de veredas da bacia do rio do Formoso, município de Buritizeiro, Minas Gerais. Geonomos, v. 18, n. 2, p. 78-85. 2010. Disponível em: https://pdfs.semanticscholar.org/8624/ccd097cf4 a38e36922e0ad2a0988a913d0d9.pdf. Acesso em 07 dez 2019.

NASCIMENTO, E. P. Trajetória da sustentabilidade: do ambiental ao social, do social ao econômico. Estudos Avançados v. 26, n. 74, São Paulo: Portal de Revistas da USP, p.: 51-62. 2012. Disponível em: 
https://www.revistas.usp.br/eav/article/view/106 24/12366. Acesso em 06 dez. 2019.

RUSSAU, C. Abstauben in Brasilien - Deutsche Konzerne im Zwielicht, Hamburg: VSA-Verlag, 2016. 240 p.

SANTOS, O. S. H.; AVELLAR, F. C.; ALVES, M.; TRINDADE, R. C.; MENEZES, M. B.; FERREIRA, M. C.; FRANÇA, G. S.; CORDEIRO, J.; SOBREIRA, F. G.; YOSHIDA, I. M.; MOURA, P. M.; BAPTISTA, M. B.; SCOTTI, M.R. Understanding the Environmental Impact of a Mine Dam Rupture in Brazil: Prospects for Remeditation. Journal of Environmental Quality. Technical Reports. Jan. 2019. Disponível em: https://dl.sciencesocieties.org/publications/jeq/p dfs/48/2/439. Acesso em 09 dez 2019.

SEGURA, F. R.; NUNES, E. A.; PANIZ, F. P.; PAULELli, A. C. C.; RODRIGUES, G. B.; BTAGA, G. U. L.; PEDREIRA-FILHO, W. R.; BARBOSA JR, F.; CERCHIARO, G.; SILVA, F. F.; BATISTA, B.L. Potential risks of the residue from Samarco's mine dam burst (Bento Rodrigues, Brazil). Environmental Pollution, 218, 813-825, 2016.

SOUZA, M. T. S.; RIBEIRO, H. C. M. Sustentabilidade Ambiental: uma Meta-análise da Produção Brasileira em Periódicos de Administração, $R A C$, Rio de Janeiro, v. 17, n. 3, art. 6, p.: 368-396, Mai./ Jun. 2013. Disponível em:http://www.scielo.br/pdf/rac/v17n3/a07v17n 3. Acesso em 06 dez 2019.

TULLER, M. P. (Org.). Colatina: folha SE.24-Y-CVI: estado do Espírito Santo. Brasília: DNPM. CPRM. Programa de Levantamentos Geológicos Básicos do Brasil- PLGB. Escala 1:100.000. 1993. Disponível em: http://rigeo.cprm.gov.br/xmlui/handle/doc/8566 ?show=full. Acesso em $08 \mathrm{dez} 2019$. 